\title{
Identification of Petroleum Degrading Bacteria and Construction of Petroleum Degrading Agent
}

\author{
Xingling Tao', Yabin Zhan', Tao Jiang2* ${ }^{2 *}$ Chuanjiong $\mathrm{Hu}^{3 *}$ \\ ${ }^{1}$ College of Life Science, Yangtze University, Jingzhou, China \\ ${ }^{2}$ College of Animal Science, Yangtze University, Jingzhou, China \\ ${ }^{3}$ Cooperative Innovation Center of Unconventional Oil and Gas, Yangtze University, Wuhan, China \\ Email: 1593654140@qq.com, ${ }^{\star}$ jt64129@163.com, ${ }^{\star}$ cjhu2012@163.com
}

How to cite this paper: Tao, X.L., Zhan, Y.B., Jiang, T. and Hu, C.J. (2019) Identification of Petroleum Degrading Bacteria and Construction of Petroleum Degrading Agent. Open Access Library Journal, 6: e5335. https://doi.org/10.4236/oalib.1105335

Received: March 14, 2019

Accepted: April 8, 2019

Published: April 11, 2019

Copyright ( 2019 by author(s) and Open Access Library Inc.

This work is licensed under the Creative Commons Attribution International License (CC BY 4.0).

http://creativecommons.org/licenses/by/4.0/

\section{c) (i) Open Access}

\begin{abstract}
The aim of this study is to construct petroleum degrading agent (PDA) which can effectively degrade oil. By enrichment, domestication, and separation of culture from the soil sample of Qianjiang Guanghua Oilfield, the pure culture of three petroleum degrading bacteria G-40, G-53, and G-94 was identified from the medium supplemented with oil, which served as the sole source of carbon. The species of G-40 and G-53 were preliminarily identified and classified by morphological observation, physiological and biochemical determination, and sequence analyses of $16 \mathrm{~S}$ rDNA. The species of G-94 was preliminarily identified and classified by morphological observation, physiological and biochemical determination, and sequence analyses of ITS rDNA. The optimal inoculation proportion of these three bacteria strains and bran proportion in composition of PDA were determined through orthogonal test. G-40, G-53, and G-94 were isolated and identified as Brevibacillus laterosporus, Tsukamurella inchonensis, and Candida tropicalis, respectively. To construct petroleum degrading agent, the optimum inoculation proportion of the three bacteria strains was A1B3C3 (G-40:G-53:G-94 = 1:4:4); and the optimum proportion of bran was D1E1F2 (soybean meal:corn flour:bran $=1: 1: 2$ ). The oil removal rate of the constructed petroleum degrading agent reached to $42.32 \%$ on day 10 under the optimal proportion of bacteria inoculation and bran composition. Petroleum degrading bacteria can effectively degrade petroleum for its own growth. This study identified three petroleum degrading bacteria strains and proposed a petroleum degrading agent by studying the optimal inoculation proportion of the three bacterial strains and the accompanying bran. Our research could provide potential microbial resources for bioremediation of petroleum-contaminated soil.
\end{abstract}




\section{Subject Areas}

Environmental Sciences, Microbiology

\section{Keywords}

Petroleum Degrading Bacteria, Petroleum Degrading Agent, Degradation

Characteristics

\section{Introduction}

Petroleum oil is a major energy source all over the world. It is a complex mixture of wide variety of different compounds including normal alkanes (n-alkanes), cyclic alkanes (c-alkanes), polyaromatic hydrocarbons (PAHs), and non-hydrocarbon compounds [1]. Petroleum oil contamination due to mismanagement of oil-production well poses serious environment problems which could also affect human health [2]. Petroleum hydrocarbons are considered very hazardous to living organism due to their toxicity, mutagenicity, and carcinogenicity [3].

Bioremediation technology including biodegradation is considered a noninvasive and relatively cost-effective approach to alleviate petroleum caused pollution of the environment [4]. Biodegradation by natural population of microorganisms represents one of the primary mechanisms by which petroleum and other hydrocarbon pollutants can be removed from the environment. In addition, it is cheaper than other remediation technologies, making it the most efficient and environment-friendly decontamination method [5] [6].

Bioremediation of petroleum-contaminated soils by natural population of microorganisms has been reported in many studies. There are about more than 30 genera and 200 species that can degrade oil in nature, including bacteria, fungi, and yeasts, among which bacteria are the main species identified. Oil degrading bacteria mainly include Saccharomyces $s p$, Bacillus $s p$, Rhodococcus $s p$, Pseudomonas sp, Sphingomonas sp, Acinetobacter sp, Alcaligenes sp, Mirococcus $s p$, and Nocardia $s p$, et al. [7] [8] [9] [10]. It is of great interest to utilize oil degrading bacteria to remove oil contamination in the environment. Although it is advantageous over bacterial fluid for its easier transportation and handling, bioremediation of petroleum-contaminated soils by solid degrading agent is rarely utilized in practice. In this study, we constructed petroleum degrading mixed bacteria agent, which showed effective oil-degrading capability.

\section{Materials and Methods}

\subsection{Source of Bacteria Isolation}

The G-40 (Brevibacillus laterosporus, accession number KY949476) and G-94 (Candida tropicalis, accession number KY949478) were isolated from Qianjiang Guanghua Oilfield in June 2015 and stored in the laboratory of College of Life Science, Yangtze University [11]. 
The G-53 was isolated from oil-contaminated soil sample. Soil samples were collected into $500 \mathrm{ml}$ sterilized glass bottles from eight sites in Qianjiang Guanghua Oilfield in June 2015. After collection, they were immediately transported to the laboratory and stored in a refrigerator at $4{ }^{\circ} \mathrm{C}$ prior to use.

\subsection{Sample}

Oil-contaminated soil sample is from Qianjiang Guanghua Oilfield.

\subsection{Bran Feed}

Soybean meal, corn flour, and bran with no mildew, rot, or moth bite were used in this study.

\subsection{Media}

Oil medium (0.5\% oil) was prepared according to [12].

Beef peptone liquid medium, beef peptone agar medium, and potato sucrose liquid medium were prepared according to [13].

\subsection{Isolation of Bacteria}

$5 \mathrm{~g}$ oil-contaminated soil sample was inoculated in $100 \mathrm{ml}$ oil medium in a 250 $\mathrm{ml}$ Erlenmeyer flask and cultured at $35^{\circ} \mathrm{C}$ on a horizontal shaker (150 rpm). After 5-day incubation, $5 \mathrm{ml}$ of sample from primary enrichment medium was subcultured to a fresh $100 \mathrm{ml}$ oil medium and incubated at the same condition. After three rounds of subculturing in oil medium, $0.1 \mathrm{ml}$ of enrichment culture was plated at appropriate dilution on beef peptone agar medium and incubated at $37^{\circ} \mathrm{C}$ for $24 \mathrm{~h}$. Single colony appeared on the medium plates were translated on a fresh beef peptone agar medium for incubation. Isolated single colony was stored at $4^{\circ} \mathrm{C}$ on beef peptone agar medium and subcultured at 3-week intervals or mixed with $40 \%$ glycerol and stored at $-80^{\circ} \mathrm{C}$ for future use [12].

\subsection{Strain Enrichment Culture}

G-40 and G-53 were inoculated into beef peptone liquid medium and G-94 was inoculated into potato sucrose liquid medium and cultured on a horizontal shaker (150 rpm) at $35^{\circ} \mathrm{C}$ for $48 \mathrm{~h}$. The bacterial culture was stored at $4^{\circ} \mathrm{C}$ for future experiments.

\subsection{Determination of Biomass}

Biomass was monitored by measuring the optical density at $420 \mathrm{~nm}$ with a TU-1900 spectrophotometer [14].

\subsection{Determination of Petroleum Removal Rate}

The oil removal rate was determined by gravimetric method [15].

\subsection{Culture Characteristics and Cell Morphology}

The colony characteristic of G-53 ( $3 \mathrm{~d}$ ) was observed on the beef peptone agar 
plate and the cell morphology was observed under microscope after gram staining.

\subsection{Physiological and Biochemical Tests}

The physiological and biochemical properties of the strain G-53 were determined according to the microbiological test method described by [13].

\subsection{Molecular Biology Assay}

The 16S rDNA gene of colony G-53 was amplified by PCR using the universal primers 27F and 1492R [16] and Thermo Scientific Phusion Flash High-Fidelity kit. The amplified 16S rDNA gene was sequenced by Sangon Biotech (Shanghai, China) Co. Ltd. The sequence similarity was analyzed by Blast on the National Centre for Biotechnology Information (NCBI). The phylogenetic tree was constructed with software MEGA5.0.

\subsection{Determination of Bacteria Inoculation Proportion by Orthogonal Experiment}

Three factors and three levels of orthogonal experiment (Table 1) of G-40, G-53, and G-94 were tested on a horizontal shaker $(150 \mathrm{rpm})$ at $35^{\circ} \mathrm{C}$. After 5 days of incubation, biomass was determined by measuring the optical density at $420 \mathrm{~nm}$ with a TU-1900 spectrophotometer.

\subsection{Determination of Bran Proportion by Orthogonal Experiment}

Three factors and three levels of orthogonal experiment (Table 2) of soybean meal, corn flour, and bran were tested. $10 \%$ (v:v) bacterial fluid was added to the bran with $2 \%$ sucrose. After incubation for 10 days at $35^{\circ} \mathrm{C}$, the PDA was filtered through $0.45 \mathrm{~mm}$ sieve and stored in sterile bags. $1 \%(\mathrm{~m}: \mathrm{v})$ inoculum of PDA was added to oil medium for 5 day incubation on a horizontal shaker (150 rpm) at $30^{\circ} \mathrm{C}$. Biomass was monitored by measuring the optical density at $420 \mathrm{~nm}$ with a TU-1900 spectrophotometer.

Table 1. Factor levels table of bacteria inoculum proportion.

\begin{tabular}{cccc}
\hline & $\mathrm{A}$ & $\mathrm{B}$ & $\mathrm{C}$ \\
\hline 1 & $0.5 \%$ & $0.5 \%$ & $0.5 \%$ \\
2 & $1.0 \%$ & $1.0 \%$ & $1.0 \%$ \\
3 & $2.0 \%$ & $2.0 \%$ & $2.0 \%$ \\
\hline
\end{tabular}

A: G-40; B: G-53; C: G-94..

Table 2. Factor levels table of bran proportion.

\begin{tabular}{cccc}
\hline & $\mathrm{D}$ & $\mathrm{E}$ & $\mathrm{F}$ \\
\hline 1 & $10 \%$ & $10 \%$ & $10 \%$ \\
2 & $20 \%$ & $20 \%$ & $20 \%$ \\
3 & $30 \%$ & $30 \%$ & $30 \%$ \\
\hline
\end{tabular}

D: soybean meal; E: corn flour; F: bran. 


\subsection{Verification Test}

The oil removal rate of PDA was tested after 10-day incubation under optimum inoculation proportion of bacteria and bran proportion.

\section{Results and Analysis}

\subsection{Culture Characteristics}

After 3 days of bacteria cultivation, colony morphology of G-53 is shown in (Figure 1).

\subsection{Cell Morphology}

The physiological and biochemical characteristic of G-53 is shown in (Table 3).
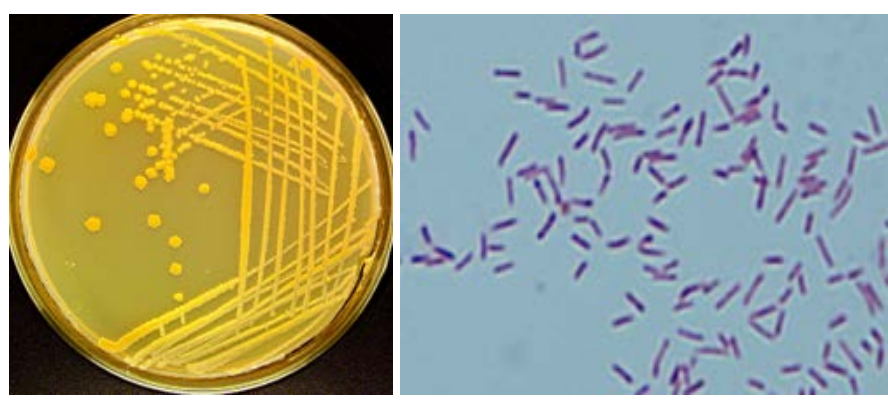

Figure 1. Morphology of G-53.

Table 3. Morphology and culture characteristics of G-53.

\begin{tabular}{cc} 
Number & G-53 \\
Morphology & Rhizoidal \\
Colour & Orange \\
Texture & Rough \\
Protuberance & Flat \\
Edge & Crimp \\
Diameter(mm) & 3.16 \\
Area (mm ${ }^{2}$ & 6.71 \\
Gelatin liquefaction & - \\
Indole & - \\
$\mathrm{H}_{2} \mathrm{O}_{2}$ & + \\
Citrate & - \\
M.R. & - \\
V.P. & + \\
Starch hydrolysis & - \\
Lipid hydrolysis & - \\
Ammonia production & + \\
Nitrate reduction & - \\
Phenylalanine dehydrogenase & + \\
$\mathrm{H}_{2} \mathrm{~S}$ & + \\
\hline
\end{tabular}

+: positive; -: negative. 


\subsection{Molecular Identification}

The 16S rDNA gene obtained from the isolates was amplified via PCR using a universal bacterial/fungal primer set. Based on the morphological observation, physiological and biochemical determination, and sequence analyses of $16 \mathrm{~S}$ rDNA sequence, G-53 was identified as Tsukamurella inchonensis (Figure 2). Accession number is KY949477.

\subsection{Determination of Bacteria Inoculation Proportion}

The G-40 and G-53 were inoculated into beef peptone liquid medium and G-94 was inoculated into potato sucrose liquid medium. The bacteria culture was incubated on a horizontal shaker $(150 \mathrm{rpm})$ at $35^{\circ} \mathrm{C}$ for $48 \mathrm{~h}$. The $\mathrm{OD}_{420}$ of G-40, G-53, and G-94 were 7.72, 2.00, and 9.87, respectively. Different inoculation proportion of the three bacteria strains showed different effect on the oil removal rate (Table 4). Maximum ratio of G-40 is the key factor affecting the oil removal rate, followed by G-94, while G-53 has the least effect. Therefore, the inoculation proportion of G-40, G-53, and G-94 in PDA for optimal oil removal was A1B3C3 (G-40:G-53:G-94 = 1:4:4).

\subsection{Determination of Bran Proportion}

Different bran proportion had obvious different effect on the oil removal rate (Table 5). Maximum range of corn flour is the key factor affecting the oil removal rate, followed by soybean meal, while bran has the least effect. Therefore, the bran proportion in PDA for optimal oil removal was D1E1F2 (soybean meal: corn flour:bran $=1: 1: 2$ ).

\subsection{Verification Test}

The result of verification test of PDA was shown in (Figure 3). Under orthogonal

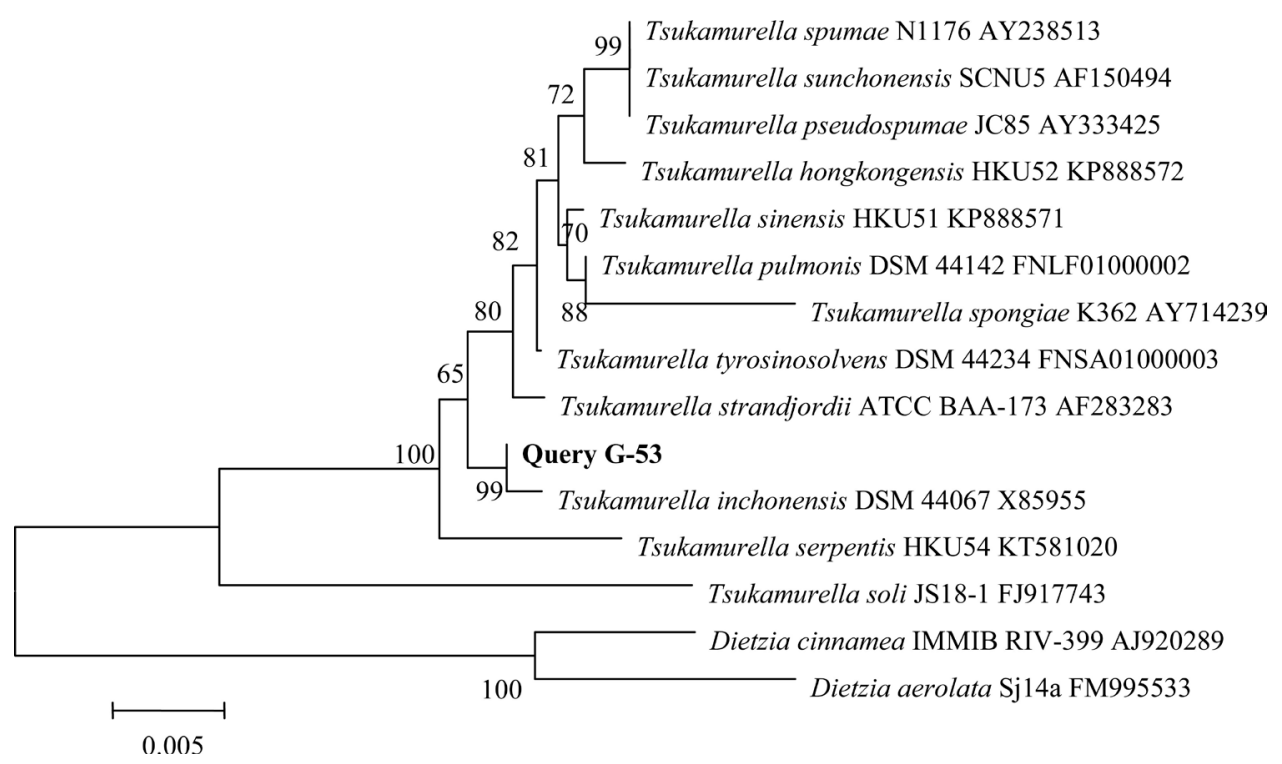

Figure 2. Neighbor-joining phylogenetic tree constructed from 16S rDNA gene sequence of G-53. 
Table 4. The orthogonal design and analysis of bacteria inoculation proportion.

\begin{tabular}{ccccc}
\hline Number & $\mathrm{A}$ & $\mathrm{B}$ & $\mathrm{C}$ & Biomass \\
\hline 1 & $0.5 \%$ & $0.5 \%$ & $0.5 \%$ & 0.161 \\
2 & $0.5 \%$ & $1.0 \%$ & $1.0 \%$ & 1.749 \\
3 & $0.5 \%$ & $2.0 \%$ & $2.0 \%$ & 2.046 \\
4 & $1.0 \%$ & $0.5 \%$ & $1.0 \%$ & 0.234 \\
5 & $1.0 \%$ & $1.0 \%$ & $2.0 \%$ & 0.263 \\
6 & $1.0 \%$ & $2.0 \%$ & $0.5 \%$ & 0.354 \\
7 & $2.0 \%$ & $0.5 \%$ & $2.0 \%$ & 0.469 \\
8 & $2.0 \%$ & $1.0 \%$ & $0.5 \%$ & 0.286 \\
9 & $2.0 \%$ & $2.0 \%$ & $1.0 \%$ & 0.380 \\
$\mathrm{~K} 1$ & 1.319 & 0.288 & 0.267 & \\
$\mathrm{~K} 2$ & 0.284 & 0.766 & 0.788 & \\
$\mathrm{~K} 3$ & 0.378 & 0.927 & 0.926 & \\
$\mathrm{R}$ & 1.035 & 0.639 & 0.659 & \\
\hline
\end{tabular}

A: G-40; B: G-53; C: G-94.

Table 5. The orthogonal design and analysis of bran proportion.

\begin{tabular}{ccccc}
\hline Number & $\mathrm{D}$ & $\mathrm{E}$ & $\mathrm{F}$ & Biomass \\
\hline 1 & $10 \%$ & $10 \%$ & $10 \%$ & 13.01 \\
2 & $10 \%$ & $20 \%$ & $20 \%$ & 9.04 \\
3 & $10 \%$ & $30 \%$ & $30 \%$ & 10.49 \\
4 & $20 \%$ & $10 \%$ & $20 \%$ & 10.30 \\
5 & $20 \%$ & $20 \%$ & $30 \%$ & 9.45 \\
6 & $20 \%$ & $30 \%$ & $10 \%$ & 12.10 \\
7 & $30 \%$ & $10 \%$ & $30 \%$ & 11.39 \\
8 & $30 \%$ & $20 \%$ & $10 \%$ & 6.25 \\
9 & $30 \%$ & $30 \%$ & $20 \%$ & 6.69 \\
K1 & 9.413 & 10.133 & 9.020 & \\
K2 & 9.117 & 6.747 & 9.343 & \\
K3 & 6.610 & 8.260 & 7.513 & \\
R & 2.803 & 3.386 & 1.830 & \\
\hline
\end{tabular}

D: soybean meal; E: corn flour; F: bran.

optimum conditions (the inoculation proportion of G-40:G-53:G-94 = 1:4:4, the bran proportion of soybean meal:corn flour:bran $=1: 1: 2$ ), the oil removal rate of PDA on $10 \mathrm{~d}$ reached up to $42.32 \%$.

\section{Discussion}

In this study, the optimal bacteria inoculation and bran proportion in petroleum 


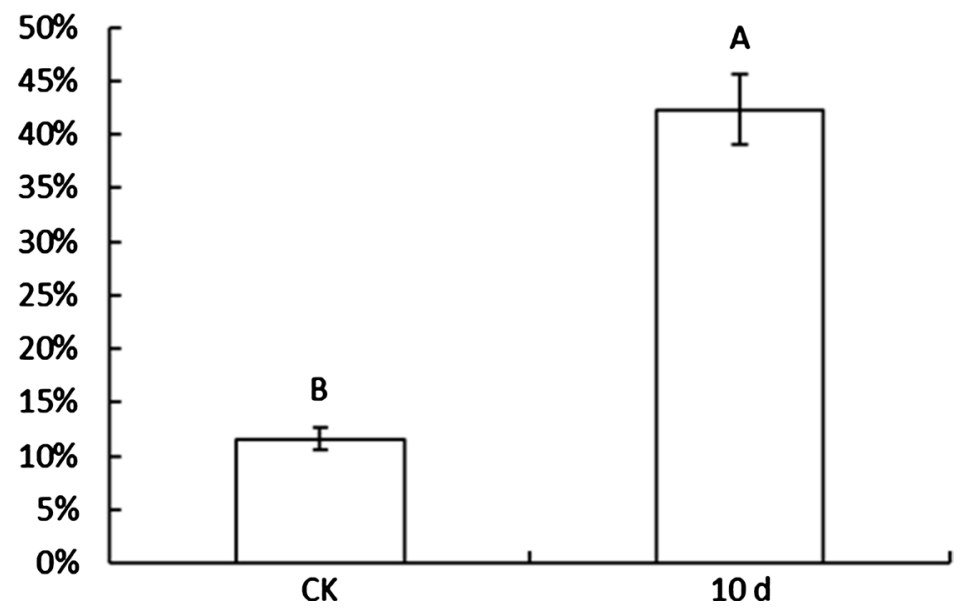

Figure 3. Oil degradation rate of mixed inoculum on $10 \mathrm{~d}$.

degrading agent were determined according to the biomass of petroleum degradation microorganism instead of the oil removal rate. It is mainly because biomass is positively correlated with oil removal rate and more convenient to be measured and monitored than oil removal rate.

The degradation of oil in the environment is possible through several techniques including physical [17], chemical [18], or biological approaches [19]. The technology commonly used for soil remediation includes mechanical, burying, evaporation, dispersion, and washing. However, these technologies are expensive and can lead to incomplete decomposition of contaminants. The process of bioremediation, defined as the use of microorganisms to detoxify or remove pollutants owing to their diverse metabolic capabilities, is an evolving method for the removal and degradation of many environmental pollutants including the products of petroleum industry [20]. In addition, bioremediation technology is believed to be noninvasive and relatively cost-effective [4]. Biodegradation by natural population of microorganisms represents one of the primary mechanisms by which petroleum and other hydrocarbon pollutants can be removed from the environment and is cheaper than other remediation technologies, making it the most efficient approach for environment safe depollution [5] [6]. Brevibacillus laterosporus, Tsukamurella inchonensis, and Candida tropicalis were used for environmental management, biological medicine, and food fermentation [21] [22] [23] [24] [25]. However, the bacterial fluid is inconvenient for transportation. Therefore, we developed microbial agents with G-40, G-53, and G-94. The optimal proportion of the three bacteria strains as well as the bran was determined with orthogonal designed experiments to effectively degrade petroleum. When the inoculation proportion of G-40:G-53:G-94 is 1:4:4 and the bran proportion of soybean meal:corn flour:bran is $1: 1: 2$, the oil removal rate of the constructed PDA reached up to $42.32 \%$ on day 10 after bacteria cultivation.

\section{Conflicts of Interest}

The authors declare no conflicts of interest regarding the publication of this paper. 


\section{References}

[1] Aboushanab, R.A., Eraky, M. and Haddad, A.M. (2016) Characterization of Crudeoil Degrading Bacteria Isolated from Contaminated Soils Surrounding Gas Stations. Bulletin of Environmental Contamination and Toxicology, 97, 684-688. https://doi.org/10.1007/s00128-016-1924-2

[2] Chan, Y., Jun, Y. and Minmin, C. (2014) Polycyclic Aromatic Hydrocarbons Degrading Microflora in a Tropical Oil-Production Well. Bulletin of Environmental Contamination and Toxicology, 93, 632-636. https://doi.org/10.1007/s00128-014-1371-x

[3] Cohen, J.H., Mccormick, L.R. and Burkhardt, S.M. (2014) Effects of Dispersant and Oil on Survival and Swimming Activity in a Marine Copepod. Bulletin of Environmental Contamination and Toxicology, 92, 381-387. https://doi.org/10.1007/s00128-013-1191-4

[4] April, T.M., Foght, J.M. and Currah, R.S. (2000) Hydrocarbon-Degrading Filamentous Fungi Isolated from Flare Pit Soils in Northern and Western Canada. Canadian Journal of Microbiology, 46, 38-49. https://doi.org/10.1139/cjm-46-1-38

[5] Al-Sayegh, A., Al-WahaibiEmail, Y., Al-Bahry, S., Elshafie, A., Al-Bemani, A. and Joshi, S. (2015) Microbial Enhanced Heavy Crude Oil Recovery through Biodegradation Using Bacterial Isolates from an Omani Oil Field. Microbial Cell Factories, 14, 141-151. https://doi.org/10.1186/s12934-015-0330-5

[6] Leahy, J.G. and Colwell, R.R. (1990) Microbial Degradation of Hydrocarbons in the Environment. Microbiological Reviews, 52, 305-315.

[7] Esmaeil, A.L.S., Drobiova, H. and Obuekwe, C. (2009) Predominant Culturable Crude Oil-Degrading Bacteria in the Coast of Kuwait. International Biodeterioration \& Biodegradation, 63, 400-406. https://doi.org/10.1016/j.ibiod.2008.11.004

[8] Jurelevicius, D., Alvarez, V.M. and Peixoto, R. (2013) The Use of a Combination of alkB Primers to Better Characterize the Distribution of Alkane-Degrading Bacteria. PLoS ONE, 8, e66565. https://doi.org/10.1371/journal.pone.0066565

[9] Guibert, L.M., Loviso, C.L. and Marcos, M.S. (2012) Alkane Biodegradation Genes from Chronically Polluted Subantarctic Coastal Sediments and Their Shifts in Response to Oil Exposure. Microbial Ecology, 64, 605-616.

https://doi.org/10.1007/s00248-012-0051-9

[10] Jurelevicius, D., Cotta, S.R. and Peixoto, R. (2012) Distribution of Alkane-Degrading Bacterial Communities in Soils from King George Island, Maritime Antarctic. European Journal of Soil Biology, 51, 37-44. https://doi.org/10.1016/j.ejsobi.2012.03.006

[11] Zhan, Y.B., Ma, L.A. and Tao, X.L. (2017) Isolation and Identification of Two Strains of Petroleum Degrading Bacteria. Journal of Yangtze University, 14, 61-64.

[12] Li, B.M., Ruan, Z.Y. and Jiang, R.B. (2007) Screen and Identification of Oil Degrading Bacteria and Community Construction. Soil and Fertilizer Sciences in China, 3, 68-72.

[13] Zhao, B. and He, S.J. (2002) Microbiology Experiment. Science Press, Beijing.

[14] Sawadogo, A., Otoidobiga, H.C. and Nitiema, L.W. (2014) Isolation and Characterization of Hydrocarbon-Degrading Bacteria from Wastewaters in Ouagadougou, Burkina Faso. Journal of Environmental Protection, 5, 1183-1196. https://doi.org/10.4236/jep.2014.512115

[15] Zhan, Y.B., Zhang, Q. and Chen, K.L. (2017) Isolation and Construction of Petroleum-Degrading Flora and Their Degrading Characteristics. Environmental Pollu- 
tion and Control, 39, 860-864+868.

[16] Liu, H., Yao, J. and Yuan, Z. (2014) Isolation and Characterization of Crude-OilDegrading Bacteria from Oil-Water Mixture in Dagang Oil Field, China. International Biodeterioration \& Biodegradation, 87, 52-59.

https://doi.org/10.1016/j.ibiod.2013.11.005

[17] Laorrattanasak, S., Rongsayamanont, W. and Khondee, N. (2016) Production and Application of Gordonia westfalica GY40 Biosurfactant for Remediation of Fuel Oil Spill. Water, Air, \& Soil Pollution, 227, 325-337.

https://doi.org/10.1007/s11270-016-3031-8

[18] Chu, W. and Kwan, C.Y. (2003) Remediation of Contaminated Soil by a Solvent/ Surfactant System. Chemosphere, 53, 9-15. https://doi.org/10.1016/S0045-6535(03)00389-8

[19] Hamme, J.D.V., Singh, A. and Ward, O.P. (2003) Recent Advances in Petroleum Microbiology. Microbiology and Molecular Biology Reviews, 67, 503-549. https://doi.org/10.1128/MMBR.67.4.503-549.2003

[20] Medinabellver, J.I., Marın, P. and Delgado, A. (2005) Evidence for in Situ Crude Oil Biodegradation after the Prestige Oil Spill. Environmental Microbiology, 7, 73-781.

[21] Barsby, T., Kelly, M.T. and Andersen, R.J. (2002) Tupuseleiamides and Basiliskamides, New Acyldipeptides and Antifungal Polyketides Produced in Culture by a Bacillus laterosporus Isolate Obtained from a Tropical Marine Habitat. Journal of Natural Products, 65, 1447-1451. https://doi.org/10.1021/np0201321

[22] Oliveira, E.J.D., Rabinovitch, L. and Monnerat, R.G. (2004) Molecular Characterization of Brevibacillus laterosporus and Its Potential Use in Biological Control. Applied and Environmental Microbiology, 70, 6657-6664. https://doi.org/10.1128/AEM.70.11.6657-6664.2004

[23] Huang, X., Tian, B. and Niu, Q. (2005) An Extracellular Protease from Brevibacillus laterosporus G4 without Parasporal Crystals Can Serve as a Pathogenic Factor in Infection of Nematodes. Research in Microbiology, 156, 719-727. https://doi.org/10.1016/j.resmic.2005.02.006

[24] Yoshizawa, K. (1978) Treatment of Waste-Water Discharged from Sake Brewery Using Yeast. Journal of Fermentation Technology, 56, 389-395.

[25] Song, F.M. (2012) Application and Progress on Environmental Pollution Control Using Yeasts. Environmental Science \& Technology, 35, 71-75 + 115. 